\title{
1 Genetic diversity and population structure among oat cultivars and landraces
}

2

3 Gracia Montilla-Bascón ${ }^{1}$, Javier Sánchez-Martín ${ }^{1}$, Nicolas Rispail ${ }^{1}$, Diego Rubiales ${ }^{1}$, 4 Luis AJ Mur ${ }^{2}$, Tim Langdon ${ }^{2}$, Irene Griffiths ${ }^{2}$, Catherine Howarth ${ }^{2}$ and Elena Prats ${ }^{1}$. 5

$6{ }^{1}$ CSIC, Institute for Sustainable Agriculture, Apdo. 4084, E-14080 Córdoba, Spain.

$7 \quad{ }^{2}$ Institute of Biological, Environmental and Rural Sciences, University of Aberystwyth, $8 \quad \mathrm{UK}$

11 *To whom correspondence should be addressed:

12 Elena Prats

13 Institute for Sustainable Agriculture, CSIC, Apdo. 4084, E-14080 Córdoba, Spain.

14

$15 \quad$ E-mail: elena.prats@ias.csic.es

16 Tel: +34957499291

17 Fax: +34957499252

18

19 


\section{$1 \quad$ Abstract}

2 In this study genetic diversity among 177 oat (Avena sativa L.) accessions including

3 both, white and red oats landraces and 36 commercial cultivars, was studied for simple

4 sequence repeat (SSR) loci. Thirty one genomic and expressed sequence tags (EST)

5 derived primer pairs were selected according high polymorphism from an initial 66 SSR

6 batch. Markers revealed a high level of polymorphism, detecting a total of 454 alleles.

7 The average gene diversity for the whole sample was 0.29 . Genetic similarity,

8 calculated using the Dice coefficient, was used for cluster analysis and principal

9 component analysis was also applied. In addition, population structure using a Bayesian

10 clustering approach identified discrete subpopulation based on allele frequency and

11 showed similar clustering of oat genotypes in four groups. Accessions could be

12 classified into four main clusters that clearly separated the commercial cultivars, the red

13 oats landraces and two clusters of white oat landraces. Cultivars showed less diversity

14 than the landraces indicating a reduction of genetic diversity during breeding, whereas

15 white oat landraces showed higher diversity than red ones. The average polymorphic

16 information content of 0.80 for the SSR loci indicated the usefulness of many of the

17 SSR for genotype identification. In particular two markers, MAMA5 and AM04, with a

18 total of 50 alleles and a high discrimination power $(>0.90)$ were sufficient to

19 discriminate among all commercial cultivars studied highlighting their potential use for

20 variety identification.

22 Keywords: A. sativa, genetic diversity, oat, simple sequence repeat (SSR), 


\section{$1 \quad$ Introduction}

2

4 L. is the main cultivated oat including the white and red oats. White oats are preferred

5 for milling and are used for human food and for fodder, especially poultry and horses.

6 Red oats (formerly known as A. byzantina K. Koch) are preferred for hay (Stevens et al. 7 2004).

9 During the $20^{\text {th }}$ century, landraces have increasingly been replaced by modern 10 cultivars, resulting in significant reduction in genetic diversity (Warburton et al. 2008;

11 Reif et al. 2005; Roussel et al. 2004) and contributing to the stability in genetic diversity 12 of wheat, barley and maize cultivars in recent years (Christiansen et al. 2002; Donini et 13 al. 2000; Koebner et al. 2003). Thus, the loss of genetic diversity has become an 14 important problem both in natural plant populations and in important crop species. This 15 loss led to calls for the genetic conservation of crop germplasm (Frankel and Bennett 16 1970). Current molecular characterization of ex situ plant germplasm has placed more 17 emphasis on cultivated gene pools and less on exotic gene pools representing wild 18 relative species (Karp 2002). Although these modern cultivars may be higher yielding 19 under high input systems, landraces have considerable potential for use in improving 20 disease and abiotic stress tolerance. Transfer of beneficial traits from landraces is 21 relatively straight-forward in that there is no barrier to crossing as there can be with the 22 use of crop wild relatives. Thus, several studies suggest that landraces may be a good 23 source of new allelic diversity for breeding programmes. However, better 24 characterization of exotic germplasm is needed to facilitate its use in plant breeding and 
1 in research (Hawkes 1990; Jellen and Leggett 2006), so as to the introgression of exotic

2 germplasm into a plant breeding program.

Genetic diversity studies, assessed by various tools including DNA markers, 5 provide important information both for genetic conservation and for use in efficiently 6 breeding new commercial varieties. To date, genetic studies in hexaploid oat has been 7 more difficult than in other species, mainly due to large genome size (Bennett and 8 Smith 1976) and polyploidy causing inherent complexities for mapping including a 9 large numbers of linkage groups, detection of multiple loci by a single probe, and co10 migration of fragments from different loci that can impede interpretation of allelic 11 relationships and genetic analyses (Iannucci et al. 2011). Amplified fragment length 12 polymorphisms (AFLPs) (Achleitner et al. 2008; Fu et al. 2005; Fu and Williams 2008), random amplified polymorphic DNA (RAPDs) (Baohong et al. 2003; Paczos-Grzeda 2004) and microsatellites have been previously used in oat for assessment of genetic diversity. In particular, microsatellites have been used to dissect genetic diversity in several Avena spp. (Li et al. 2000; Li et al. 2007) and to examine allelic diversity changes over 100 years of oat breeding in both Nordic countries (Nersting et al. 2006), Canada (Fu et al. 2007) and North Europe (He and Bjornstad 2012). Association of genetic markers with regions of the genome controlling different traits would enable efficient and precise transfer of useful alleles from landraces to modern cultivars whilst minimizing linkage drag of non- beneficial alleles.

To date identification of oat cultivars has relied on morphological and 24 phenological characteristics that may be influenced by environmental factors and 25 require trained staff and large-scale growth experiments of mature plants under uniform 
1 conditions for evaluation. In addition some cultivars are morphologically similar,

2 making difficult to distinguish between them visually. SSR profiles can be used as a

3 DNA fingerprint for registered cultivars to avoid redundancy of identical cultivars as

$4 \quad$ well as to protect breeders' rights.

5

6

Here, we studied the genetic diversity of 141 white and red oat landraces together with 36 currently grown oat cultivars for potential use in breeding programmes. Furthermore we tested the potential of SSRs for molecular identification of the oat cultivars studied.

\section{Plant material \\ Plant material}

\section{Materials and methods}

A germplasm collection of landraces consisting of 141 A. sativa accessions (110 white and 31 red oats) originally collected from 1944 to 1997 in southern Spain, when they were used locally in agriculture (Online Resource 1), was provided by the "Plant Genetic Resources Center” (CRF-INIA, Madrid, Spain). In addition, 36 commercial cultivars were supplied by the Andalusian Network of Agriculture Experimentation (RAEA) selected for their adaptation to southern Spain agroecological conditions. For simplicity, germplasm bank codes were substituted for the codes included in Supplementary Table 1 (Sánchez-Martín et al. 2011a). White oat cultivars studied were Ac1, Acebeda, Adamo, Aintree, Alcudia, Anchuela, Araceli, Brawi, Caleche, Canelle, Chambord, Chapline, Charming, Cobeña, Condor, Cory, Edelprinz, Flega, Fringante, Fuwi, Hammel, Kankan, Kantora, Karmela, Cassandra, Kazmina, Mirabel, Mojacar, 
1 Norlys, Orblanche, Pallini, Patones, Prevision, Primula, and Rapidena. In addition, the

2 A. strigosa cultivar Saia was included for comparison.

3

Seedlings were grown in $0.5 \mathrm{~L}$ pots filled with peat:sand $(3: 1)$ in a growth 5 chamber at $20^{\circ} \mathrm{C}, 65 \%$ relative humidity and under $12 \mathrm{~h}$ dark $/ 12 \mathrm{~h}$ light with $150 \mu \mathrm{mol}$

$6 \mathrm{~m}^{-2} \mathrm{sec}^{-1}$ photon flux density supplied by high-output white fluorescent tubes. Sites and

7 year of landraces sampling together with other characteristics of the site are recorded in

8 Online Resource 1 and year of registration, origin, and genealogy if known of cultivars

$9 \quad$ are recorded in Online Resource 2.

DNA extraction, SSR markers and PCR procedure

Ten leaves from 12-day-old seedlings were harvested and DNA extracted according to the CTAB protocol (Murray and Thompson 1980). Sixty-six SSR primer pairs derived from genomic and EST libraries of oats and barley were selected from previous reports to test for polymorphism (Becher 2007; Jannink and Gardner 2005; Li et al. 2000; Liu et al. 1996; Pal et al. 2002; Wight et al. 2010). In addition, 3 SSR were

18 developed from EST sequence information, from Avena barbata and Festuca by using 19 the following primers: Barb2-40, (5'-CCATCTCAACCTTTGCTTCTCTCCT-3' and 5'-GTTCTTGAGCTCCTTGACCTTGAGC-3'); Barb4-10, (5'-GCTGAGCAATCTCA TCAGCTCAACT-3' and 5'-GAGGTGATCCGAGCTTACTTCATCA-3'); Fesc12, (5'-GTCGCCGGAGAAGAGAAGAG-3' and 5'-AACGCTAGCCGTGATGACTT-3').

23 Following preliminary assays in a subset of 46 samples a final set of 31 primer pairs

24 (Table 1) were chosen because of their consistency in amplification and polymorphism 25 in our oat genotypes and/or because they had been mapped in a mapping population 
1 developed from two winter oat cultivars Buffalo and Tardis (data not shown) and

2 displayed reasonable genome coverage.

3

4

Amplification reactions were set up for 40 cycles with an initial denaturing step of $10 \mathrm{~min}$ at $95^{\circ} \mathrm{C}$. Each cycle consisted of denaturation at $94{ }^{\circ} \mathrm{C}$ for $1 \mathrm{~min}$, followed by primer-specific annealing for $1 \mathrm{~min}$ (temperature specified in Table 1) and extension at $72{ }^{\circ} \mathrm{C}$ for $1 \mathrm{~min}$. After 35 cycles, there was a final extension step of $10 \mathrm{~min}$ at $72{ }^{\circ} \mathrm{C}$. The $10 \mu \mathrm{L}$ reaction mix comprised $6.05 \mu \mathrm{L}$ sterile-distilled water, $0.05 \mu \mathrm{L}$ Taq polymerase (Roche Applied Sciences, Mannheim, Germany), $1 \mu \mathrm{L}$ of 10x PCR buffer with $\mathrm{MgCl}_{2}, 1.3 \mu \mathrm{L}$ of dNTP (5 mM equimolar solution of each dATP, dCTP, dGTP and dTTP), $0.3 \mu \mathrm{L}$ each of forward and reverse primers (10 $\mu \mathrm{M}$ solution) and $1 \mu \mathrm{L}$ of template DNA (30 ng $\mu \mathrm{L}^{-1}$ ). Reactions were stopped with $95 \%$ formamide loading dye. Amplification products from markers AME097, AME105, AME168, AME176, AME192, BarbSSR_2-40, and BarbSSR_4-10 were separated on 4.5\% polyacrylamide denaturing gel (BIO-RAD, California, USA, Sequi-GenGT, $38 \times 50 \mathrm{~cm}$ ) using 73-well comb and visualized by silver staining (Promega Silver Sequencing system, Wisconsin, USA). Relative movement of different amplicons and standard molecular-weight marker was used to estimate the sizes of amplified fragments using regression. The remained markers were run on the ABI 3137 capillary sequencer. PCR, using AmpliTag gold, was conducted as for polyacrylamide gel analysis except that one primer was labeled with a fluorescent dye and the concentration of DNA was $20 \mathrm{ng} \mu \mathrm{L}^{-1}$. The size standard Genescan500 $\mathrm{LIZ}^{\mathrm{TM}}$ (orange) was included with each sample and used to determine the sizes of the PCR products detected. All primers and the size standards were supplied by Applied Biosystems (ABI). Data were analysed using Genemapper (ABI). Presence or absence of each amplified band was scored as 1 and 0 , respectively, 
1 for all markers to generate a binary data matrix. The genetic diversity of each

2 microsatellite locus was assessed by calculating the frequency of the microsatellite

3 alleles based on polymorphic information content (PIC) following (Botstein et al. 1980)

4 using the equation:

$5 \quad \mathrm{PIC}=1-\mathrm{J}=1-\sum_{J=1}^{n} P^{2} \mathrm{ij}$

6 where $P \mathrm{ij}$ is the frequency of the $j^{\text {th }}$ allele for $i^{\text {th }}$ marker. Estimates of genetic similarity

7 (GS) were calculated for all possible pairs of genotypes according to Dice similarity

8 coefficient (Nei and Li 1979). In addition, frequencies of incidence of all polymorphic

9 alleles for each SSR marker were calculated and used for determining statistical

10 parameters. Confusion probability $(\mathrm{Cj})$ and discriminating power $(\mathrm{Dj})$ of each marker

11 were estimated according to Tessier et al. (1999). Cluster analysis based on unweighted

12 pair-group method with arithmetic average (UPGMA) was performed on matrix of GS

13 estimates using GenStat $7^{\text {th }}$ Edition and a dendrogram constructed. The correlation

14 coefficient between the similarity matrix and the cophenetic values matrix was

15 computed to test the goodness of fit of the cluster analysis. NTSYS-pc $2.02 \mathrm{j}$ software

16 (Biostatistics Inc., USA, Rohlf 1998) was used for these statistical analyses.

Population structure and percentages of admixture

20 Population structure was inferred by the software STRUCTURE 2.3.3. We set most 21 parameters to their default values as advised in the user's manual (Pritchard and Wen 22 2003). Specifically, we chose the admixture model and the option of correlated allele 23 frequencies between populations, as this configuration is considered best in cases of 24 subtle population structure (Falush et al. 2003). Similarly, we let the degree of 25 admixture alpha be inferred from the data. Each simulation included 10,000 burn-in and 
1100,000 iterations. Longer burn-in or MCMC did not change significantly the results.

2 Ten independent simulations per $\mathrm{k}$ value were run and the mean estimate across runs of

3 the $\log$ posterior probability of the data for a given $k, \operatorname{Pr}(X \mid k)$, called $L(k)$ were plotted

4 for each k category on a graph to determine the k value of the population as the value of

$5 \mathrm{k}$ for which the distribution of $\mathrm{L}(\mathrm{k})$ plateaus or continues to increase, but much more

6 slowly. Because this point is known to be difficult to determine, we also used $\Delta \mathrm{k}$, an ad

7 hoc quantity proposed by Evanno et al. (2005) related to the second order rates of

8 change of the likelihood function with respect to k that is supposed to show a clear $\Delta \mathrm{k}$

9 at true value of $k$. The percentages of admixture of each accession ( $Q$ matrix) given by

10 the software were used as cofactors in the association analyses. For trait analyses per

11 subpopulation, an accession was assigned to a subpopulation when it showed more than

$1280 \%$ membership in this subpopulation (Figueiredo et al. 2010).

\section{Results}

16 The thirty-one primer pairs used to characterize and evaluate the genetic diversity in the

17 landraces and commercial varieties of the oat collection showed a high level of 18 polymorphism, displaying a total of 454 alleles. The total number of alleles per marker ranged from 3 for AME168 to 42 for MAMA05 with a mean of 14.65 (Table 1). PIC varied from 0.46 (AME168 and AM112) to 0.96 (AM04) with a mean of 0.80. Based on

21 PIC values obtained, most SSRs, with the exception of AM112, AME168, AME176, 22 BarbSSR_2-40 and BarbSSR_4-10, were considered informative markers (PIC $>0.7$ ), 23 indicating the potential use of this set of SSR markers for cultivar identification (Table 24 1). Allelic frequencies observed ranged from 0.001 to 0.69 with a mean of 0.062 . One 25 hundred thirty eight alleles out of 454 detected were classified as "rare" due to their low 
1 frequency $(<0.03)$, 194 were classified as "common", with frequencies between 0.03

2 and 0.2 , and 122 were classified as "more frequent" with frequencies $>0.2$ (Table 1 ).

3 Rare and common alleles were detected at 26 and 27 SSR loci studied, respectively.

4 Rare alleles per locus ranged from 0 to 16 (MAMA05) whereas the number of common

5 alleles per locus ranged from 0 to 28 (AM04) and the more frequent from 0 to 9

6 (AM30) (Table 1). High values of discriminating power ( $\mathrm{Dj} \geq 0.81)$ and $\mathrm{PIC} \geq 0.81$, and

7 low values of confusion probability $(\mathrm{Cj} \leq 0.19)$ were obtained for 20 of the markers

8 evaluated $(64.5 \%)$ (Table 1$)$.

9

From the dendrogram generated, the 177 accessions could be classified into four

11 main clusters that clearly separated the commercial cultivars, the red oats landraces and

12 two clusters of white oat landraces (Fig 1). The $A$. strigosa genotype, Saia, did not cluster with the A. sativa entries. Genetic similarity estimates calculated among the oat collection varied from 0.16 to a maximum of 0.99 (between Gen130 and Gen131) with

a mean similarity of 0.29 (Figure 1). Cluster 1 included most of the commercial 16 cultivars together with the landraces Gen141 and Gen17. Cultivars with the highest 17 genetic similarity (0.88) were Chapline and Cobeña. Cluster 2 comprised the red oat landraces along with the commercial red oat cultivars Cassandra and Prevision. In

19 addition four landraces, Gen139, Gen64, Gen27, Gen106 which are all described as 20 white oats were included in this cluster. The red oat landrace Gen84 however grouped 21 in cluster 3 . The third and fourth cluster included most of the white oat landraces. The 22 third cluster contained 51 genotypes with Gen5 and Gen 13 being the most related 23 landraces with a GS of 0.84 . The fourth cluster was the largest with 53 genotypes. 24 Genetic similarity within each cluster was similar with values of $0.50,0.55,0.50$ and 250.54 for cluster $1,2,3$, and 4 respectively but when comparing the white oats, 
1 commercial cultivars had a slightly higher GS compared with landraces. Most clusters

2 showed particular alleles characteristic for that group. For example, most genotypes of

3 cluster 1 had the 209 bp allele from AM01 marker, all genotypes of cluster two had the

$4 \quad 137$ and 368 bp alleles from AME097 and MAMA3 marker, all genotypes from cluster

$5 \quad 3$ and 4 except one had the $232 \mathrm{pb}$ allele amplified with AM112 marker, but only

6 genotypes from cluster 3 had the $161 \mathrm{pb}$ allele amplified with AM87. Overall,

7 comparison of the white oats revealed 22 unique alleles belonging to commercial

8 cultivars and 129 to landraces. In addition 11 alleles were assigned exclusively to the

9 red oat landraces. Analysis of the allelic frequency obtained for each marker showed

10 that often clusters 2,3 , or 4 associated with landraces had a significantly higher allelic

11 frequency than cluster 1 (Table 2). In particular markers AME105 and MAMA 9

12 showed significantly higher allelic frequences in clusters 2, 3 and 4 compared with

13 cluster 1 . Only for marker MAMA11 was the allelic frequency of cluster 1 higher than

14 that of clusters 2, 3, and 4 (Table 2). Comparison between the cophenetic matrix and the

15 similarity matrix was significant with $\mathrm{r}^{2}=0.876(\mathrm{p}<0.01)$ indicating a high goodness of

16 fit between both matrices.

Interestingly, when assessing independently the oat cultivars, a subset of 11 markers (HvXan, AM01, AM30, AM14, AM87, AM07, MAMA08, AM42, MAMA5, AM04, FESC12) showed a high polymorphism with 167 alleles and high PIC (>0.80).

21 This subset of SSRs were able to group the white oat cultivars from cluster 1 showing 22 similar genetic relationship among them as obtained when assessed with the complete 23 SSR set. Furthermore, among these SSRs, two of them MAMA5, with 23 alleles and a 24 discriminating power of 0.90 , and AM04, with 27 alleles and a discrimination power of 250.94 , were sufficient to discriminate between all cultivars. 
2 Structure of the population

3

4 The criteria used to define the number of subpopulations in the oat collection, which are

5 the position of a break point in the $\mathrm{L}(\mathrm{k})$ curve and a peak in the $\Delta \mathrm{k}$ distribution,

6 supported values of $\mathrm{k}=2$ and $\mathrm{k}=4$ (data not shown). For both $\mathrm{k}$ values, most

7 accessions were assigned by STRUCTURE to a subpopulation. With $\mathrm{k}=2$, it was

8 possible to distinguish between the white oat landraces and the rest of the collection.

9 With $\mathrm{k}=4$, a finer sub-grouping corresponding to the commercial varieties, the red oat

10 landraces, and two groups of white oat landraces was obtained. Figure 2 shows the 4

11 subpopulations detected by STRUCTURE with the percentage of admixture of each

12 genotype in the corresponding subpopulation. The results of the assignments showed a

13 very good congruence between the two methods. Indeed, only 3 out of the 177

14 genotypes assessed, Saia, Gen51 and Gen61, were assigned to different clusters by

15 UPGMA and STRUCTURE approaches and in the three cases STRUCTURE

16 coefficients indicated a membership lower than $80 \%$ in the corresponding population.

17 According to STRUCTURE, subpopulation 1 showed the lowest degree of admixture

18 with only $16.2 \%$ of the genotypes with less than $80 \%$ of membership to this

19 subpopulation followed by subpopulation 2 with $28.6 \%$ of genotypes with less than

$2080 \%$ of membership in this group. Subpopulation 3 and 4 , with 31.4 and $34.6 \%$ of

21 genotypes with less than $80 \%$ membership to the corresponding subpopulation, were the

22 subpopulation with higher admixture. In addition the germplasm collection were also

23 subjected to multivariate analysis based on principal component analysis (PCAs) and

24 discriminant function analysis (DFAs) which revealed clear separation of 4

25 subpopulations which indicate a high consistency of the data (Figure 3). 


\section{Discussion} revealed high variability among accessions. However, this variability was more evident

6 within the white oat landrace collection with 129 exclusive alleles, followed by the red 7 oat landraces, and the cultivars, with 11 and 22 exclusive alleles respectively. This 8 indicates the considerable genetic variation that exists in landraces that is not present in

9 the cultivars and offers opportunities for breeding new cultivars by exploiting the genetic diversity existing in the landraces. Our findings on clear distinctions between

11 white and red oat landraces are in agreement with previous reports ( $\mathrm{Fu}$ et al. 2005;

12 Newell et al. 2011; Odonoughue et al. 1994) and support the hypothesis that white and 13 red oats were domesticated independently of each other (Zohary and Hopf 2000).

14 White oat landraces were more distinct from the white oat cultivars, however red oat 15 landraces grouped together with the red oat cultivars analyzed (Figure 1) suggesting 16 either lower improvement of the red oats cultivars compared with the white or the 17 involvement of the nearest genetic similar red landraces in their genealogy.

In general, most of the accessions closely related by pedigree and/or derived

20 from germplasm having specific traits, clustered together. Thus, those cultivars with the 21 highest genetic similarity from cluster 1 shared common ancestors. For instance, 22 Mirabel, Aintree, Caleche and Norlys shared Fringante as one of their parent. In 23 addition, Norlys and Caleche shared other common ancestors. Other closely related 24 cultivars such as AC1 and Orblanche had Mostyn as a common ancestor. Furthermore, 25 Orblanche together with Condor, Fuwi and Adamo comprise a subcluster with a genetic 
1 similarity of 0.7 . This result may be explained by their common genealogy, since

2 Orblanche and Adamo had Condor as an ancestor, and Adamo and Fuwi shared the

3 cultivar Manod in their genealogy. There is less information about ancestry for the

4 landrace collection, but geographic location of the collection sites is known (Online

5 Resource 1). Cluster 2 grouped most red oat accessions but also four landraces

6 described as white oats, Gen139, Gen64, Gen27 and Gen106 that also shared the $235 \mathrm{pb}$

7 allele amplified by AM112 exclusive to this group. A detailed analysis of the

8 morphological characters that differentiate white and red oats (Magness et al. 1971)

9 showed that indeed Gen139, Gen64 and Gen27 in addition of the color of the seeds had

10 the typical white oats morphological characters such as no basal scar in the spikelets

11 from the separation from pedicel, twisted awns, and small glumes. However, Gen106

12 was morphologically nearer to red oat showing weak and non-twisted awns. The

13 geographic proximity of these white oat accessions with their most related red oat

14 landraces suggests a possible cross between the landraces so that the white landraces

15 would have acquired some of the exclusive alleles of cluster 2. Indeed, Gen64 (white

16 oat) and Gen65 (red oat) were sampled from the same locality while Gen106 (white oat)

17 and Gen132 (red oat) were sampled at sites with only $8 \mathrm{~km}$ between them. Interestingly,

18 the white oat landraces grouped in 2 clusters, 3 and 4. A detailed analysis of alleles

19 showed high differences between these two clusters. For instance, more than $95 \%$ of

20 genotypes of cluster 3 had the alleles BarbSSR4_10-4, MAMA3-2; AM87-15 and

21 AM04-11 whereas less than 15\% of the genotypes of cluster 4 had them. By contrary

22 more than $95 \%$ of genotypes from cluster 4 had the alleles BarbSSR_4_10-2, AME192-

233 and AME192-5 whereas less than $30 \%$ of genotypes of cluster 3 had them. In order to

24 determine the possible causes of these differences we plotted the geographic distribution

25 of the landraces. No differences in latitude or longitude could be inferred between the 
1 two clusters but landraces of cluster 3 were distributed in locations with significantly

2 higher altitude than those of cluster 4 (average of $537 \mathrm{~m}$ altitude for cluster 3 and $377 \mathrm{~m}$

3 for cluster $4 ; P=0.01$ ). This suggests a different evolution for the two clusters, with

4 cluster 3 better adapted to higher altitudes and their associated cooler temperatures and

5 probably poorer soils than cluster 4 .

6

The narrow separation observed in this study among the $A$. sativa cultivars bred in European countries suggests that a rather small proportion of the available genetic variation from this species is currently used for oat improvement, as seen by Achleitner et al. (2008) in an oat collection of worldwide origin. A similar lack of diversity were also detected within sets of Canadian and Chinese oat varieties (Baohong et al. 2003; Fu et al. 2004) leading Fu and coworkers (2004) to identify an urgent need to broaden the genetic variation for sustainable oat improvement in Canada. The reduction of genetic diversity may have consequences both for the vulnerability of crops to new pests and pathogens and for their ability to respond to changes in climate and agricultural practices $(\mathrm{Fu}$ et al. 2003). Most of the landraces studied in this work have been characterised for disease and abiotic stress resistance (Sanchez-Martin et al. 2011a; Sanchez-Martin et al. 2011b) revealing accessions with interesting resistance that would be valuable to include in European cultivars. Study of mechanisms underlying resistance in selected landraces and varieties has been also performed (Sanchez-Martin et al. 2011a; Sanchez-Martin et al. 2011b) and the oat collection was also tested under a variety of Mediterranean environments for agronomic adaptation (unpublished results). The increased use of these accessions in European and/or Mediterranean breeding programs could simultaneously increase diversity and improve levels of valuable traits. From crosses of genetically divergent parents (i.e. a high yielding cultivar crossed with 
1 a landrace showing disease and drought resistance) novel varieties with improved traits

2 might be selected.

3

Methods such as UPGMA presented here, which do not assume predefined

5 structure, are only loosely connected to statistical procedures allowing the identification

6 of homogeneous clusters of individuals. For that reason, the oat germplasm collection

7 was also analysed using an alternative model-based method implemented in the

8 software STRUCTURE (Pritchard et al. 2000), which uses a Bayesian approach to

9 simultaneously determine $\mathrm{k}$ (the number of subpopulations in a collection), and estimate

10 for each accession the proportion of its genome that originates from each subpopulation,

11 also called percentage of admixture. The model accounts for the presence of Hardy-

12 Weinberg assumption or linkage disequilibrium by introducing population structure and

13 attempts to find population groupings that (as far as possible) are not in disequilibrium

14 (Pritchard et al. 2000).

Structure was detected in this germplasm collection using both classical

17 multivariate and Bayesian analyses. The patterns obtained with the two methods were

18 very similar. Population structure is the primary obstacle to successful association

19 studies in any organism (Buckler and Thornsberry 2002). Model-based clustering

20 suggests that a large amount of the allelic diversity can be described by subdividing the

21 accessions into 4 discrete populations, where each subpopulation has a unique set of

22 allele frequencies. This method is clearly a simplification of the observed data;

23 however, it can be used to compare with other methods of clustering, and to test models

24 of association analysis that would account for genetic associations arising from structure 
1 presence. The congruence of patterns obtained with Bayesian and multivariate analyses

2 suggests that the estimates of these admixture proportions are reasonably reliable.

In other cereal crops such as corn (Gunjaca et al. 2008) and rice (Bonow et al. 2009), molecular profiles associated with the description of a cultivar have been used to

6 enforce the rights granted to breeders. The two selected markers MAMA5 and AM04

7 show great potential for identifying cultivars since they were able to discriminate

8 between the 36 cultivars tested, some of them with relatively high genetic similarity,

9 sharing common genealogy. Thus, our findings suggest that microsatellite markers can

10 play an important role as a source of additional information in oat to supplement the

11 morphological descriptors recommended by International Union for the Protection of

12 New Varieties of Plants (UPOV).

14 Acknowledgments

15 This work was supported by the Spanish Ministry of Economy and Competitiveness 16 [AGL2010-15936/AGR], the European Social and Regional Development Funds, a JAE 17 PreDoc fellowship from CSIC to [GMB], a JAE Postdoctoral Fellowship from CSIC to $18[\mathrm{NR}]$ and a FPU fellowship from the Spanish Ministry of Science and Innovation to 19 [JSM]. We thank CRF (INIA, Madrid) for kindly supply the seeds of the accessions 20 used.

\section{References}

Achleitner A, Tinker NA, Zechner E, Buerstmayr H (2008) Genetic diversity among oat varieties of worldwide origin and associations of AFLP markers with 
quantitative traits. Theor Appl Genet 117 (7):1041-1053. doi:10.1007/s00122008-0843-y

Baohong G, Zhou X, Murphy JP (2003) Genetic variation within Chinese and western cultivated oat accessions. Cereal Res Commun 31 (3-4):339-346

Becher R (2007) EST-derived microsatellites as a rich source of molecular markers for oats. Plant Breeding 126 (3):274-278. doi:10.1111/j.1439-0523.2007.01330.x

Bennett MD, Smith JB (1976) Nuclear-DNA amounts in angiosperms. Philos T Roy Soc B 274 (933):227-274

Bonow S, Von Pinho EVR, Vieira MGC, Vosman B (2009) Microsatellite markers in and around rice genes: applications in variety identification and DUS testing. Crop Sci 49 (3):880-886

Botstein D, White RL, Skolnick M, Davis RW (1980) Construction of a genetic-linkage map in man using restriction fragment length polymorphisms. Am J Hum Gen $32(3): 314-331$

Buckler ES, Thornsberry JM (2002) Plant molecular diversity and applications to genomics. Curr Opin Plant Biol 5 (2):107-111. doi:10.1016/s1369$5266(02) 00238-8$

Christiansen MJ, Andersen SB, Ortiz R (2002) Diversity changes in an intensively bred wheat germplasm during the 20(th) century. Mol Breeding 9 (1):1-11. doi:10.1023/a:1019234323372

Donini P, Law JR, Koebner RMD, Reeves JC, Cooke RJ (2000) Temporal trends in the diversity of UK wheat. Theor Appl Genet 100 (6):912-917. doi: $10.1007 / \mathrm{s} 001220051370$ 
1 Evanno G, Regnaut S, Goudet J (2005) Detecting the number of clusters of individuals using the software STRUCTURE: a simulation study. Mol Ecol 14 (8):26112620. doi:10.1111/j.1365-294X.2005.02553.x

Falush D, Stephens M, Pritchard JK (2003) Inference of population structure using multilocus genotype data: Linked loci and correlated allele frequencies. Genetics 164 (4):1567-1587

Figueiredo LFD, Sine B, Chantereau J, Mestres C, Fliedel G, Rami JF, Glaszmann JC, Deu M, Courtois B (2010) Variability of grain quality in sorghum: association with polymorphism in Sh2, Bt2, SssI, Ae1, Wx and O2. Theor Appl Genet 121 (6):1171-1185. doi:10.1007/s00122-010-1380-z

Frankel OH, Bennett E (1970) Genetic Resources in Plants-Their Exploration and Conservation. Blackwell Scientific Publications, Oxford

Fu YB, Peterson G, Scoles G, Rossnagel B, Schoen D, Richards K (2003) Allelic diversity changes in 96 Canadian oat cultivars released from 1886 to 2001. Crop Sci 43:1989-1995

Fu YB, Kibite S, Richards KW (2004) Amplified fragment length polymorphism analysis of 96 Canadian oat cultivars released between 1886 and 2001. Can J Plant Sci 84 (1):23-30

Fu YB, Peterson GW, Williams D, Richards KW, Fetch JM (2005) Patterns of AFLP variation in a core subset of cultivated hexaploid oat germplasm. Theor Appl Genet 111 (3):530-539. doi:10.1007/s00122-005-2044-2

Fu YB, Peterson GW, Chong J, Fetch T, Wang ML (2007) Microsatellite variation in Avena sterilis oat germplam. Theor Appl Genet 114:10229-1038

Fu YB, Williams DJ (2008) AFLP variation in 25 Avena species. Theor Appl Genet 117 (3):333-342 
1 Gunjaca J, Buhinicek I, Jukic M, Sarcevic H, Vragolovic A, Kozic Z, Jambrovic A, Pejic I (2008) Discriminating maize inbred lines using molecular and DUS data. Euphytica 161:165-172

4 Hawkes JG (1990) The potato: evolution, biodiversity and genetic resources. Belhaven Press, London, England

6 He X, Bjornstad A (2012) Diversity of North European oat analyzed by SSR, AFLP and DArT markers. Theor Appl Genet 125 (1):57-70. doi:10.1007/s00122-012-18168

Iannucci A, Codianni P, Cattivelli L (2011) Evaluation of genotype diversity in oat germplasm and definition of ideotypes adapted to the mediterranean

Jannink JL, Gardner SW (2005) Expanding the pool of PCR-based markers for oat. Crop Sci 45 (6):2383-2387. doi:10.2135/cropsci2005.0285

Jellen EN, Leggett JM (2006) Cytogenetic manipulation in oat improvement. In: Singh environment. Int J Agron 2011:8. doi:doi:10.1155/2011/870925

RJ, Jauhar JJ (eds) Genetic resources, chromosome engineering, and crop improvement: Cereals, vol 2. CRC press, pp 199-231

Karp (2002) The new genetic era: will it help us in managing genetic diversity? In: Engels JMM, Ramanatha Rao V, Brown AHD, Jackson MT (eds) Managing Plant Genetic Diversity. CAB International and IPGRI, Wallingford and Rome, pp 43-56

Koebner RMD, Donini P, Reeves JC, Cooke RJ, Law JR (2003) Temporal flux in the morphological and molecular diversity of UK barley. Theor Appl Genet 106 (3):550-558. doi:10.1007/s00122-002-1065-3 
1 Li CD, Rossnagel BG, Scoles GJ (2000) The development of oat microsatellite markers and their use in identifying relationships among Avena species and oat cultivars. Theor Appl Genet 101:1259-1268

4 Li RZ, Wang SW, Duan LS, Li ZH, Christoffers MJ, Mengistu LW (2007) Genetic diversity of wild oat (Avena fatua) populations from China and the United States. Weed Sci 55 (2):95-101. doi:10.1614/ws-06-108.1

7 Liu ZW, Biyashev RM, Maroof MAS (1996) Development of simple sequence repeat DNA markers and their integration into a barley linkage map. Theor Appl Genet 93 (5-6):869-876. doi:10.1007/bf00224088

Magness JR, Markle GM, Compton CC (1971) Food and feed crops of the United States. In. Interregional Research Project IR-4, IR Bul. 1 (Bul. 828.New Jersey Agric. Expt. Sta.),

Murray MG, Thompson WF (1980) Rapid isolation of high molecular-weight plant DNA. Nucleic Acids Res 8 (19):4321-4325. doi:10.1093/nar/8.19.4321

Nei M, Li WH (1979) Mathematical-model for studying genetic-variation in terms of restriction endonucleases. Proc Natl Acad Sci USA 76 (10):5269-5273

Nersting LG, Andersen SB, von Bothmer R, Gullord M, Jorgensen RB (2006) Morphological and molecular diversity of Nordic oat through one hundred years of breeding. Euphytica 150 (3):327-337. doi:10.1007/s10681-006-9116-5

Newell MA, Cook D, Tinker NA, Jannink JL (2011) Population structure and linkage disequilibrium in oat (Avena sativa L.): implications for genome-wide association studies. Theor Appl Genet 122 (3):623-632. doi:10.1007/s00122010-1474-7 
1 Odonoughue LS, Souza E, Tanksley SD, Sorrells ME (1994) Relationships among 2 North-American oat cultivars based on restriction-fragment-lengthpolymorphisms. Crop Sci 34 (5):1251-1258

4 Paczos-Grzeda E (2004) Pedigree, RAPD and simplified AFLP-based assessment of genetic relationships among Avena sativa L. cultivars. Euphytica 138 (1):13-22. doi:10.1023/B:EUPH.0000047055.99322.7a

7 Pal N, Sandhu JS, Domier LL, Kolb FL (2002) Development and characterization of 8 microsatellite and RFLP-derived PCR markers in oat. Crop Sci 42 (3):912-918

Pritchard JK, Stephens M, Donnelly P (2000) Inference of population structure using multilocus genotype data. Genetics 155 (2):945-959

Pritchard JK, Wen W (2003) Documentation for STRUCTURE software: Version 2. . Available from http://pritchbsduchicagoedu

Reif JC, Zhang P, Dreisigacker S, Warburton ML, van Ginkel M, Hoisington D, Bohn M, Melchinger AE (2005) Wheat genetic diversity trends during domestication and breeding. Theor Appl Genet 110 (5):859-864. doi:10.1007/s00122-004$1881-8$

Roussel V, Koenig J, Beckert M, Balfourier F (2004) Molecular diversity in French bread wheat accessions related to temporal trends and breeding programmes. Theor Appl Genet 108 (5):920-930. doi:10.1007/s00122-003-1502-y

Sanchez-Martin J, Rubiales D, Prats E (2011a) Resistance to powdery mildew (Blumeria graminis f.sp avenae) in oat seedlings and adult plants. Plant Pathol 60 (5):846-856. doi:10.1111/j.1365-3059.2011.02453.x

Sanchez-Martin J, Rubiales D, Sillero JC, Prats E (2011b) Identification and characterization of sources of resistance in Avena sativa, A. byzantina and $A$. strigosa germplasm against a pathotype of Puccinia coronata f.sp. avenae with 
3 Stevens EJ, Armstrong KW, Bezar HJ, Griffin WB, J.G. H (2004) Fodder oats an

virulence against the Pc94 resistance gene. Plant Pathol. doi:10.1111/j.13653059.2011.02514.x overview. In: Suttie JM, Reynolds SG (eds) Fodder oats: A world overview. Food and Agriculture Organization of the United Nations, Rome, pp pp. 1-9

Tessier C, David J, This P, Boursiquot JM, Charrier A (1999) Optimization of the choice of molecular markers for varietal identification in Vitis vinifera $\mathrm{L}$. Theor Appl Genet 98 (1):171-177. doi:10.1007/s001220051054

Warburton ML, Peif JC, Frisch M, Bohn M, Bedoya C, Xia XC, Crossa J, Franco J, Hoisington D, Pixley K, Taba S, Melchinger AE (2008) Genetic diversity in CIMMYT nontemperate maize germplasm: Landraces, open pollinated varieties, and inbred lines. Crop Sci 48 (2):617-624. doi:10.2135/cropsci2007.02.0103

Wight CP, Yan WK, Fetch JM, Deyl J, Tinker NA (2010) A set of new simple sequence repeat and Avenin DNA markers suitable for mapping and fingerprinting studies in oat (Avena spp.). Crop Sci $50 \quad$ (4):1207-1218. doi: $10.2135 /$ cropsci2009.09.0474

Zohary D, Hopf M (2000) Domestication of plants in the old world. Third edn. Oxford University Press, Oxford-New York 
Table 1: Characteristics of 31 microsatellite markers selected for use in the study. Size range, number of alleles (rare, common and most frequent), confusion probability $(\mathrm{Cj})$, discriminating power $(\mathrm{Dj})$ and polymorphic information content (PIC).

\begin{tabular}{|c|c|c|c|c|c|c|c|c|c|c|c|}
\hline Marker name & SSR type & $\mathbf{T m}$ & Detection $^{c}$ & Size (pb) & $\mathbf{N}^{0}$ alleles & $\begin{array}{c}\text { Rare } \\
\text { alleles } \\
(<0,03)\end{array}$ & $\begin{array}{c}\text { Common } \\
\text { alleles } \\
(\mathbf{0 , 0 3 - 0 . 2 )}\end{array}$ & $\begin{array}{c}\text { Frequent } \\
\text { alleles } \\
(>0,2)\end{array}$ & $C j$ & $D j$ & PIC \\
\hline AM01 & Genomic & 55 & ABI & $154-240$ & 27 & 10 & 14 & 3 & 0.11 & 0.89 & 0.89 \\
\hline AM03 & Genomic & 58 & $\mathrm{ABI}$ & $249-298$ & 22 & 7 & 15 & 0 & 0.06 & 0.94 & 0.93 \\
\hline AM04 & Genomic & & $\mathrm{ABI}$ & $78-180$ & 41 & 7 & 28 & 6 & 0.04 & 0.96 & 0.96 \\
\hline AM07 & Genomic & 55 & ABI & $146-195$ & 25 & 8 & 13 & 4 & 0.08 & 0.92 & 0.92 \\
\hline AM102 & Genomic & 55 & ABI & $160-217$ & 10 & 2 & 3 & 5 & 0.18 & 0.82 & 0.82 \\
\hline AM112 & Genomic & & $\mathrm{ABI}$ & $227-255$ & 7 & 3 & 3 & 1 & 0.54 & 0.46 & 0.46 \\
\hline AM14 & Genomic & 55 & $\mathrm{ABI}$ & $98-134$ & 17 & 4 & 5 & 8 & 0.10 & 0.90 & 0.90 \\
\hline AM30 & Genomic & 55 & $\mathrm{ABI}$ & $178-230$ & 17 & 3 & 5 & 9 & 0.11 & 0.89 & 0.89 \\
\hline AM42 & Genomic & 58 & ABI & $165-208$ & 13 & 4 & 1 & 8 & 0.14 & 0.86 & 0.86 \\
\hline AM87 & Genomic & 55 & ABI & $92-171$ & 15 & 6 & 3 & 6 & 0.17 & 0.83 & 0.83 \\
\hline AM89 & Genomic & 53 & ABI & $173-201$ & 10 & 3 & 2 & 5 & 0.22 & 0.78 & 0.77 \\
\hline AME097 & EST & 52 & Silver & $145-155$ & 4 & 0 & 0 & 4 & 0.26 & 0.74 & 0.74 \\
\hline AME105 & EST & 52 & Silver & $140-190$ & 10 & 0 & 5 & 5 & 0.13 & 0.87 & 0.87 \\
\hline AME168 & EST & 52 & Silver & $200-220$ & 3 & 0 & 1 & 2 & 0.54 & 0.46 & 0.46 \\
\hline AME176 & EST & 52 & Silver & $90-110$ & 4 & 0 & 1 & 3 & 0.32 & 0.68 & 0.68 \\
\hline AME192 & EST & 52 & Silver & $300-345$ & 6 & 1 & 0 & 5 & 0.22 & 0.78 & 0.78 \\
\hline BarbSSR_2-40 & EST & 60 & Silver & $195-220$ & 4 & 0 & 0 & 4 & 0.37 & 0.63 & 0.63 \\
\hline BarbSSR_4-10 & EST & 60 & Silver & $270-310$ & 5 & 1 & 1 & 3 & 0.36 & 0.64 & 0.63 \\
\hline CDO187 & EST & 55 & ABI & $104-152$ & 9 & 3 & 0 & 6 & 0.18 & 0.82 & 0.82 \\
\hline Fesc12 & EST & 61 & ABI & $124-194$ & 21 & 7 & 12 & 2 & 0.10 & 0.90 & 0.90 \\
\hline HVM20 & Genomic & 53 & ABI & $103-154$ & 21 & 9 & 11 & 1 & 0.10 & 0.90 & 0.90 \\
\hline HvXan & EST & 50 & ABI & $93-206$ & 26 & 15 & 6 & 5 & 0.15 & 0.85 & 0.85 \\
\hline MAMA01 & Genomic & 55 & ABI & $183-215$ & 12 & 3 & 7 & 2 & 0.18 & 0.82 & 0.81 \\
\hline MAMA03 & Genomic & 55 & ABI & $351-403$ & 12 & 2 & 8 & 2 & 0.14 & 0.86 & 0.85 \\
\hline MAMA05 & Genomic & 55 & ABI & $62-274$ & 42 & 16 & 20 & 6 & 0.07 & 0.93 & 0.92 \\
\hline MAMA07 & Genomic & 55 & $\mathrm{ABI}$ & $322-371$ & 12 & 5 & 5 & 2 & 0.29 & 0.71 & 0.70 \\
\hline МАМА08 & Genomic & 55 & ABI & $548-623$ & 18 & 5 & 12 & 1 & 0.10 & 0.90 & 0.90 \\
\hline MAMA09 & Genomic & 55 & $\mathrm{ABI}$ & $401-491$ & 14 & 6 & 4 & 4 & 0.16 & 0.84 & 0.84 \\
\hline MAMA11 & Genomic & 55 & ABI & $124-183$ & 9 & 4 & 3 & 2 & 0.24 & 0.76 & 0.75 \\
\hline МАМА12 & Genomic & 55 & ABI & $297-321$ & 8 & 2 & 3 & 3 & 0.22 & 0.78 & 0.78 \\
\hline OL0410 & EST & 55 & ABI & $256-281$ & 10 & 2 & 3 & 5 & 0.19 & 0.81 & 0.81 \\
\hline Mean & & & & & 14.65 & 4.45 & 6.26 & 3.94 & 0.20 & 0.80 & 0.80 \\
\hline Total & & & & & 454 & 138 & 194 & 122 & & & \\
\hline
\end{tabular}

${ }^{\mathrm{c} A B I}$; Applied Biosystem ABI3137 
Table 2: Comparison of allelic frequency between subpopulations.

\begin{tabular}{|c|c|c|c|c|c|}
\hline \multirow[b]{2}{*}{ PRIMER } & \multicolumn{4}{|c|}{ Alellic Frecuency } & \multirow[t]{2}{*}{ Signific } \\
\hline & Cluster 1 & Cluster 2 & Cluster 3 & Cluster 4 & \\
\hline AM01 & $0,12^{\mathrm{a}}$ & $0,11^{\mathrm{a}}$ & $0,11^{\mathrm{a}}$ & $0,12^{\mathrm{a}}$ & $\mathrm{ns}$ \\
\hline AM03 & $0,05^{\mathrm{ac}}$ & $0,06^{\mathrm{ad}}$ & $0,07^{\text {bd }}$ & $0,05^{\mathrm{c}}$ & $* * *$ \\
\hline AM04 & $0,12^{\mathrm{a}}$ & $0,13^{\mathrm{a}}$ & $0,13^{\mathrm{a}}$ & $0,10^{\mathrm{b}}$ & $* * *$ \\
\hline АM07 & $0,09^{\mathrm{ab}}$ & $0,10^{\mathrm{a}}$ & $0,08^{\mathrm{b}}$ & $0,10^{\mathrm{a}}$ & ns \\
\hline AM102 & $0,21^{\mathrm{a}}$ & $0,31^{\mathrm{b}}$ & $0,23^{\mathrm{a}}$ & $0,16^{\mathrm{c}}$ & $* * *$ \\
\hline AM112 & $0,18^{\mathrm{a}}$ & $0,18^{\mathrm{a}}$ & $0,15^{\mathrm{bc}}$ & $0,15^{\mathrm{c}}$ & $* * *$ \\
\hline AM14 & $0,21^{\mathrm{a}}$ & $0,20^{\mathrm{a}}$ & $0,25^{\mathrm{b}}$ & $0,22^{\mathrm{ab}}$ & $*$ \\
\hline AM30 & $0,33^{\mathrm{a}}$ & $0,43^{\mathrm{b}}$ & $0,38^{\mathrm{c}}$ & $0,33^{\mathrm{a}}$ & $* * *$ \\
\hline AM42 & $0,32^{\mathrm{a}}$ & $0,31^{\mathrm{a}}$ & $0,36^{\mathrm{b}}$ & $0,31^{\mathrm{a}}$ & $* *$ \\
\hline AM87 & $0,14^{\mathrm{a}}$ & $0,16^{\mathrm{a}}$ & $0,18^{\mathrm{b}}$ & $0,21^{\mathrm{c}}$ & $* * *$ \\
\hline AM89 & $0,33^{\mathrm{a}}$ & $0,34^{\mathrm{a}}$ & $0,33^{\mathrm{a}}$ & $0,34^{\mathrm{a}}$ & $\mathrm{ns}$ \\
\hline AME097 & $0,36^{\mathrm{ab}}$ & $0,43^{\mathrm{a}}$ & $0,34^{\mathrm{b}}$ & $0,33^{\mathrm{b}}$ & $* * *$ \\
\hline AME105 & $0,14^{\mathrm{a}}$ & $0,26^{\mathrm{b}}$ & $0,24^{b}$ & $0,24^{b}$ & $* * *$ \\
\hline AME168 & $0,39^{a}$ & $0,44^{\mathrm{a}}$ & $0,41^{\mathrm{a}}$ & $0,53^{\mathrm{b}}$ & $* * *$ \\
\hline AME176 & $0,48^{\mathrm{a}}$ & $0,48^{\mathrm{a}}$ & $0,63^{b}$ & $0,59^{\mathrm{b}}$ & $* * *$ \\
\hline AME192 & $0,36^{\mathrm{a}}$ & $0,43^{\mathrm{b}}$ & $0,43^{\mathrm{b}}$ & $0,38^{\mathrm{a}}$ & $* *$ \\
\hline BarbSSR_2-40 & $0,32^{\mathrm{a}}$ & $0,49^{b}$ & $0,45^{\mathrm{ab}}$ & $0,52^{\mathrm{b}}$ & $*$ \\
\hline BarbSSR_4-10 & $0,40^{\mathrm{a}}$ & $0,45^{\mathrm{b}}$ & $0,43^{\mathrm{ab}}$ & $0,41^{\mathrm{a}}$ & $* * *$ \\
\hline CDO187 & $0,38^{\mathrm{a}}$ & $0,43^{b c}$ & $0,46^{\mathrm{b}}$ & $0,40^{\mathrm{ac}}$ & $* *$ \\
\hline FESC12 & $0,09^{\mathrm{a}}$ & $0,09^{\mathrm{a}}$ & $0,08^{\mathrm{a}}$ & $0,09^{\mathrm{a}}$ & ns \\
\hline HVM20 & $0,06^{\mathrm{a}}$ & $0,07^{\mathrm{a}}$ & $0,08^{\mathrm{a}}$ & $0,08^{\mathrm{a}}$ & ns \\
\hline HvXan & $0,16^{\mathrm{a}}$ & $0,15^{\mathrm{a}}$ & $0,17^{\mathrm{ac}^{\mathrm{c}}}$ & $0,19^{b c}$ & $*$ \\
\hline МАМА01 & $0,10^{\mathrm{a}}$ & $0,09^{\mathrm{ac}}$ & $0,08^{\mathrm{bc}}$ & $0,10^{\mathrm{a}}$ & $*$ \\
\hline МАМАОЗ & $0,10^{\mathrm{a}}$ & $0,11^{\mathrm{a}}$ & $0,10^{\mathrm{a}}$ & $0,16^{\mathrm{b}}$ & $* * *$ \\
\hline МАМА05 & $0,09^{\mathrm{a}}$ & $0,10^{\mathrm{ab}}$ & $0,11^{\mathrm{b}}$ & $0,08^{c}$ & $* * *$ \\
\hline МАМА07 & $0,11^{\mathrm{ab}}$ & $0,12^{\mathrm{a}}$ & $0,11^{\mathrm{ab}}$ & $0,10^{\mathrm{b}}$ & $\mathrm{ns}$ \\
\hline МАМА08 & $0,07^{\mathrm{ac}}$ & $0,08^{\mathrm{ab}}$ & $0,06^{\mathrm{c}}$ & $0,06^{\mathrm{c}}$ & ns \\
\hline МАМА09 & $0,09^{\mathrm{a}}$ & $0,13^{b}$ & $0,14^{\mathrm{b}}$ & $0,12^{\mathrm{b}}$ & $* * *$ \\
\hline MAMA11 & $0,14^{\mathrm{a}}$ & $0,11^{b}$ & $0,11^{\mathrm{b}}$ & $0,12^{\mathrm{b}}$ & $* * *$ \\
\hline МАМА12 & $0,14^{\mathrm{a}}$ & $0,17^{\mathrm{a}}$ & $0,16^{\mathrm{a}}$ & $0,22^{\mathrm{b}}$ & $* * *$ \\
\hline OL0410 & $0,32^{\mathrm{a}}$ & $0,35^{\mathrm{a}}$ & $0,40^{\mathrm{b}}$ & $0,34^{\mathrm{a}}$ & $* * *$ \\
\hline
\end{tabular}

Different letter in a row indicates significant differences at $\mathrm{p} \leq 0.05, \mathrm{p}<0.01$ and $\mathrm{p} \leq 0.001$ according to $*, * *$, and $* * *$ respectively for that marker 


\section{Figure Captions}

Fig. 1 UPGMA dendogram of 176 oat accessions based on DICE distance for 31 SSR markers

Fig. 2 Estimated population structure of oat genotypes according to STRUCTURE software. Each individual is represented by a thin vertical segment, which can be partitioned into 4 grey-scale colored segments that represent the individual estimated membership to the 4 clusters

Fig. 3 Scatterplot of Discriminant Function Analysis scores of components 1 and 2 based on 31 SSR markers used in this study. A. Represented are the genotypes belonging to cluster 1 (circles), cluster 2 (squares), cluster 3 (crosses) and cluster 4 (triangles). B. Magnification of the central part of the graph A with the groups assigned according to the DFA scores 


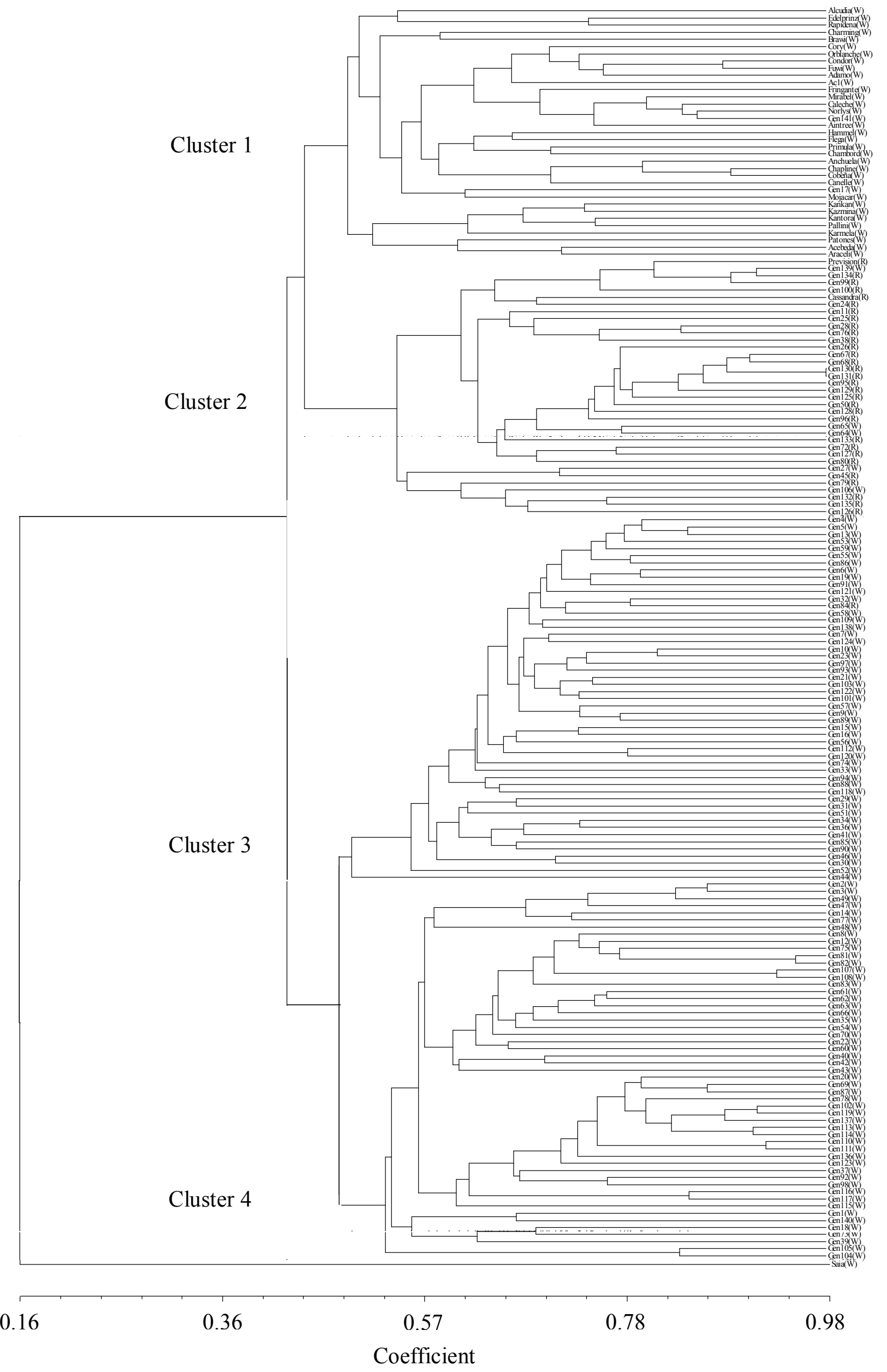

Figure 1. 


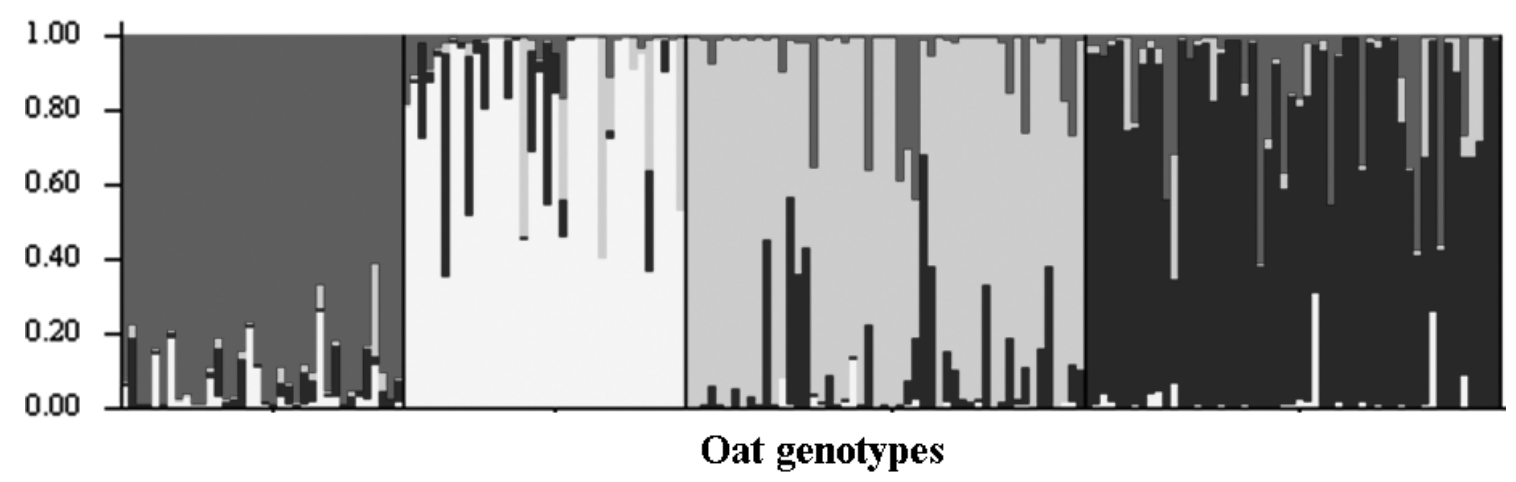

Figure 2. 

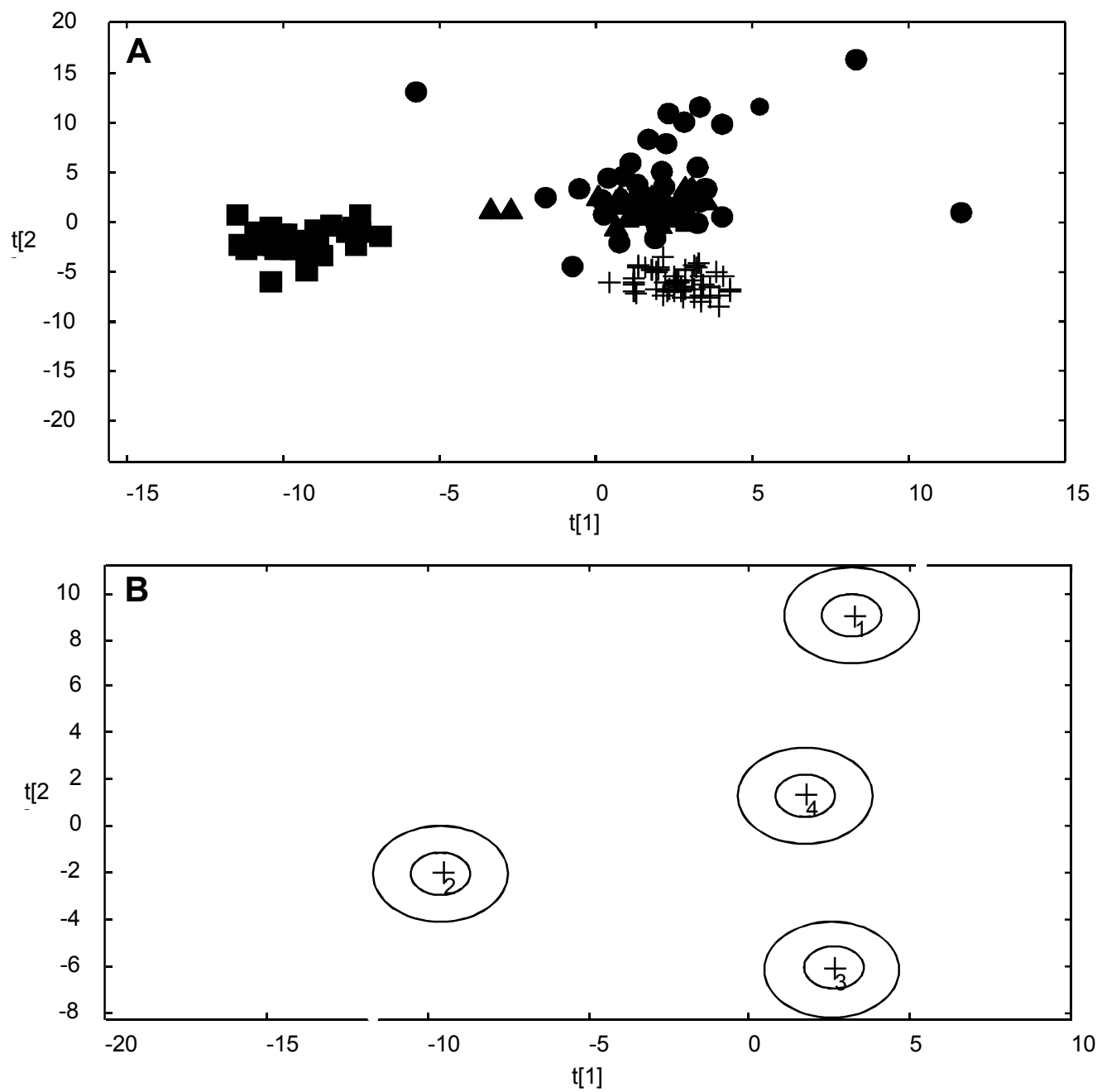

Figure 3. 